\title{
Discontinuation of Azathioprine Could Be Considered in Pediatric Patients with Crohn's Disease who Have Sustained Clinical and Deep Remission
}

\section{Tae Jong Jeong}

Department of Pediatrics, Samsung Medical Center, Sungkyunkwan University School of Medicine

\section{Eun Sil Kim}

Department of Pediatrics, Samsung Medical Center, Sungkyunkwan University School of Medicine

\section{Yiyoung Kwon}

Department of Pediatrics, Samsung Medical Center, Sungkyunkwan University School of Medicine

\section{Seonwoo Kim}

Statistics and Data Center, Samsung Medical Center

\section{Sang Won Seo}

Department of Neurology, Samsung Medical Center, Sungkyunkwan University School of Medicine

\section{Yon Ho Choe}

Department of Pediatrics, Samsung Medical Center, Sungkyunkwan University School of Medicine Mi Jin Kim ( $\nabla$ mijin1217.kim@samsung.com )

Department of Pediatrics, Samsung Medical Center, Sungkyunkwan University School of Medicine

\section{Research Article}

Keywords: Crohn's disease, Azathioprine, Infliximab, Biologics, Inflammatory bowel disease

Posted Date: June 8th, 2021

DOl: https://doi.org/10.21203/rs.3.rs-576160/v1

License: (c) (1) This work is licensed under a Creative Commons Attribution 4.0 International License. Read Full License

Version of Record: A version of this preprint was published at Scientific Reports on January 11th, 2022. See the published version at https://doi.org/10.1038/s41598-021-04304-6. 


\section{Abstract}

Few studies have demonstrated treatment strategies about the duration and cessation of medications in patients with Crohn's disease (CD). We investigated factors affecting clinical relapse after infliximab (IFX) or azathioprine (AZA) withdrawal in pediatric patients with $C D$ on combination therapy. Pediatric patients with moderate-to-severe $C D$ receiving combination therapy were analyzed retrospectively and factors associated with clinical relapse were investigated. Discontinuation of IFX or AZA was performed in patients who sustained clinical remission (CR) for at least two years and achieved deep remission. A total of 75 patients were included. Forty-four patients $(58.7 \%)$ continued with combination therapy and 31 patients (41.3\%) discontinued AZA or IFX (AZA withdrawal 10, IFX withdrawal 15, both withdrawal 6). Cox proportional-hazards regression identified four factors associated with clinical relapse: IFX cessation (hazard ratio; HR 2.982, $P=0.0081)$, formation of antibody-to-IFX (ATI) (HR=3.12, $P=0.0373)$, IFX trough level $(T L)(H R=0.581, P=0.003)$ and 6-thioguanine nucleotide (6-TGN) level $(H R=0.978, P<0.001)$. However, AZA cessation was not associated with clinical relapse $(P=0.9021)$. Even when applied in pediatric patients who meet stringent criteria, IFX cessation increased the relapse risk. However, withdrawal of AZA could be contemplated in pediatric patients with CD who have sustained CR for at least two years and achieved deep remission.

\section{Introduction}

Crohn's disease (CD) is a chronic, relapsing disease of the gastrointestinal tract that can cause serious morbidity and disability ${ }^{1}$. Current treatment trends recommend the early introduction of biologics in pediatric patients with $C D$ exhibiting severe disease ${ }^{2}$. Infliximab (IFX), one type of anti-tumor necrosis factor (TNF) agent, can be appropriate initial therapy in moderate-to-severe pediatric CD patients ${ }^{3}$. It is well known that corticosteroid-free clinical remission (CR) is more likely to be achieved in patients with moderate-to-severe CD when treated with a combination therapy that includes IFX plus azathioprine (AZA) or with IFX monotherapy, than in those receiving AZA monotherapy ${ }^{4}$. Early introduction of IFX, known as top-down therapy, is an important option for pediatric patients with moderate-to-severe $C D$ and has become the mainstay of treatment for $\mathrm{CD}^{5}$. However, since long-term use of $A Z A$ increases the risk of complications such as leukopenia, opportunistic infections, and lymphoma in children, concomitant use of immunomodulators and biologics has raised safety concerns ${ }^{6,7}$. In addition, combination therapy is not clearly associated with high efficacy after achieving long-term remission ${ }^{8}$. Despite the increasing use of combination therapy, few studies have established the optimum strategy in terms of duration and cessation of medications after achieving remission. Optimal duration and discontinuation of medications is still a matter of discussion ${ }^{9}$. Furthermore, although it is well known that concomitant treatment with immunomodulator reduces the formation of antibody-to-infliximab (ATI) and improves the pharmacokinetics of IFX, other factors affecting ATI formation are not clearly identified ${ }^{10}$.

The aim of this study was to determine factors affecting clinical relapse after achieving remission in pediatric $C D$ and to estimate the proper duration and time of cessation of early combination therapy in a 


\section{Materials \& Methods}

\section{Study design and patients}

This was a retrospective observational study conducted at the Department of Pediatrics of Samsung Medical Center in the Republic of Korea, between January 2012 and March 2018. Eligible patients had moderate-to-severe luminal CD and were aged less than 19 years at both time of diagnosis and the time of their first treatment with IFX. CD was diagnosed in accordance with the revised Porto criteria of the European Society for Pediatric Gastroenterology, Hepatology and Nutrition ${ }^{11}$ and disease phenotype classification was based on the Paris classification ${ }^{12}$. Patients on early combination therapy were included in the analysis, and patients underwent endoscopy on a regular basis every one-two years. At the same time, patients with IFX trough levels (TLs) of $3 \mu \mathrm{g} / \mathrm{mL}$ or greater before IFX cessation or at the last follow-up were included.

Patients were excluded if they were primary non-responders to IFX, or developed ATI during induction therapy of IFX. In addition, patients whose IFX TL at maintenance therapy were less than $3 \mu \mathrm{g} / \mathrm{ml}$ despite of dose intensification when they underwent endoscopy, and who were poor metabolizers of AZA according to thiopurine methyltransferase (TPMT) and nucleotide triphosphate diphosphatase 15 (NUDT15) genotype, were excluded for accurate analysis of effects of combination therapy ${ }^{13}$.

IFX was administered according to the scheduled induction regimen of $5 \mathrm{mg} / \mathrm{kg}$ at weeks 0,2 , and 6 , and scheduled maintenance IFX was repeated every 8 weeks. IFX doses were adjusted by IFX TL during maintenance therapy; if IFX TL was less than $3 \mu \mathrm{g} / \mathrm{ml}$, dose intensification was performed. Azathioprine was given at doses of $0.5-1 \mathrm{mg} / \mathrm{kg} /$ day and was later modified when required according to TPMT and NUDT15 genotype and thiopurine metabolite levels of 6-thioguanine nucleotide (6-TGN) levels (therapeutic range: $235-450)^{14}$.

Drug cessation was performed among patients who maintained CR more than two years and at the same time achieved deep remission. The decision to discontinue either IFX or AZA was determined by various requirements, such as concerns about side effects from long-term use of the medication, cost effectiveness, and patients' and parental demands. We did not selectively discontinue specific medications for specific patients.

\section{Data collection and definitions}

Demographic and clinical data at diagnosis, at combination therapy initiation, at drug cessation, and during follow-up were collected from electronic medical records: age, sex, disease phenotype, body mass index (BMI), pediatric Crohn's disease activity index (PCDAI), laboratory results, simple endoscopic score for CD (SES-CD), histologic results and concomitant medication. Date related to AZA or IFX cessation, date of clinical relapse, 6-TGN, IFX TLs, and formation of ATI were collected retrospectively from 
electronic charts or electronic test results. The data described above was used to determine factors affecting clinical relapse and to estimate the appropriate duration and time of cessation of early combination therapy.

Serum samples were obtained prior to each infusion for measurement of IFX TLs and ATI. IFX TLs and ATI were quantified using enzyme-linked immunosorbent assay (ELISA; IDK monitor ${ }^{\circledR}$ infliximab drug level ELISA and Matriks Biotek Laboratories, Ankara, Turkey). AZA concentration was estimated indirectly every 3-6 months by measuring 6-TGN levels which are considered to be the primary active metabolite of AZA.

CR was defined as a PCDAI $<10$ points. Deep remission was defined as the absence of mucosal ulceration (SES-CD < 2), i.e., mucosal healing, at the same time as the achievement of histologic remission which means the absence of microscopically active inflammation in all gastrointestinal tissue obtained by endoscopy. Clinical relapse was defined as a PCDAI score of $\geq 10$ with a change of at least 10 points from the previous visit with the need for treatment intensification, defined as either i) the addition of a new medication, (ii) dose escalation of maintenance treatment and (iii) intestinal surgery because of stricturing or penetrating $C D$.

\section{Statistical analysis}

Baseline characteristics of subjects were explored with descriptive statistics through frequencies (proportion) for categorical variables, or medians (interquartile range; IQR) for continuous variables. Data related to clinical characteristics, the duration and cessation timing of medication, 6-TGN, and IFX TLs were analyzed. The risk factors associated with clinical relapse were identified by Cox proportionalhazards regression models. Time-varying covariance occurs when covariates changes over time during the follow-up period. Drug-related factors were more appropriate to be analyzed as time-varying covariates rather than time-independent covariates because variables such as drug administration (or discontinuation) and drug concentration vary over time. Therefore, cessation and duration of medication, 6-TGN, and IFX TLs were analyzed using time-varying covariates with the Cox regression model to estimate these effects on survival time, because these were the variables that changed during the study period. For this, we organized the data in a counting process style. Hazard ratio (HR) for each variable was derived within $95 \%$ confidence intervals (Cis). The proper duration and cessation time of the treatment were estimated based on factors affecting clinical relapse, mean duration of therapy and mean time of cessation. Relapse-free curve was estimated using an extended Kaplan-Meier method that can be used with time-varying covariates ${ }^{15}$. Data were considered significantly different if two-sided $P$ was < 0.05. All statistical analyses were performed using SAS software (version 9.4; SAS Institute Inc., Cary, NC, USA) and R software (version 3.6.1; R Foundation, Vienna, Austria).

\section{Results}

\section{Baseline characteristics}


From January 2012 to March 2018, a total of 216 pediatric patients were diagnosed with CD and of these 75 patients were finally considered eligible for analysis as shown in the flow diagram for patient selection (Figure 1). Among the study participants, 48 patients (64.0\%) were male and the median age of subjects at diagnosis was 14.2 years (IQR 12.0-17.0 years). The median initial PCDAl at diagnosis was 39.7 (IQR 37.5-45.0) and median initial SES-CD was 16.9 (IQR 11.0-24.0). The median observational duration was 41.5 months (IQR 23.0-58.7 months). Other baseline characteristics are described in detail in Table 1.

\section{Relapse rate of patients according to withdrawal of medications}

Of 75 patients, 31 (41.3\%) patients met the criteria of sustained CR more than two years and the definition of deep remission, and discontinued AZA or IFX according to various requirements. Sixteen patients withdrew AZA, 21 patients IFX, and among them, six patients discontinued both. The remaining 44 patients (58.7\%) who achieved CR but did not reach deep remission, continued combination therapy with IFX and AZA (Figure 2). The mean durations of AZA and IFX therapy were $38.0 \pm 19.3$ months and $32.0 \pm 18.9$ months respectively. In the drug discontinuation group, the mean follow-up duration after AZA and IFX withdrawal was $14.0 \pm 9.5$ months and $28.0 \pm 22.9$ months respectively. When comparing the group that withdrew AZA, with the group who discontinued IFX, there was no significant difference in disease activity and laboratory results at the time of diagnosis and at the time of drug discontinuation (Table 2).

Among 75 patients, 31 (41.3\%) were clinically relapsed and 44 patients (58.7\%) maintained CR during the study period. Four of 16 patients who withdrew AZA experienced clinical relapse (4/16, 25.0\%), 15 of 21 patients who withdrew IFX experienced relapse $(15 / 21,71.4 \%)$, and four of six patients who withdrew all drugs experienced relapse $(4 / 6,66.6 \%)$. Sixteen of 44 patients $(16 / 44,36.4 \%)$ who continued IFX and AZA during study period experienced relapse.

\section{Factors associated with clinical relapse}

A Cox proportional-hazards regression identified four factors associated with clinical relapse. IFX cessation (HR 2.982, 95\% Cl=1.322-6.485, $P=0.0081$ ), formation of ATI (HR 3.120, 95\% Cl=1.069-9.103, $P=0.0373)$, low IFX TL (HR 0.581, 95\% $\mathrm{Cl}=0.432-0.781, P=0.0003)$ and low 6-TGN level (HR 0.978, 95\% $\mathrm{Cl}=0.968-0.987, P<0.0001)$ were found to increase the risk of clinical relapse. AZA cessation (HR 1.078, $95 \% \mathrm{Cl}=0.327-3.550, P=0.9021)$ was not shown to increase the risk of clinical relapse (Table 3 ).

To evaluate the relapse-free curve in relation to discontinuation of medication and ATI formation, KaplanMeier survival curves were calculated (Figure 3). Patients who discontinued IFX (Figure 3B, $P=0.0081$ ) or developed ATI (Figure 3C, $P=0.0373$ ) had significantly poorer outcomes compared to those who did not. However, there was no difference in survival rate between patients who continued or discontinued AZA (Figure 3A, $P=0.9021$ ).

\section{Factors associated with formation of antibody-to-infliximab}

Factors associated with formation of ATI during maintenance therapy were evaluated because ATI formation was a risk factor for clinical relapse. According to Cox proportional-hazards regression, only 6- 
TGN level was related to the formation of ATI (HR 0.988, 95\% Cl =0.980-0.996, $P=0.0048)$. AZA cessation (HR 17.99, 95\% Cl=0.19-1663.7, $P=0.2109$ ) was not related to formation of ATI. Within the therapeutic range $\left(235-450\right.$ pmole/ $\left.8 \times 10^{8} \mathrm{RBC}\right){ }^{14}$, high 6-TGN level is a factor that lowers the risk of developing ATI (HR 0.988, 95\% Cl=0.980-0.996, $P=0.0048$, Table 4).

\section{Discussion}

In this study, we investigated the factors affecting clinical relapse and estimated the optimum duration and time of cessation of treatment in moderate to severe pediatric CD treated with combination therapy. We identified four factors related to elevated risk of clinical relapse; IFX cessation, formation of ATI, low IFX TL and low 6-TGN level. Interestingly, withdrawal of AZA was not directly associated with clinical relapse in pediatric CD patients with sustained CR of at least two years and who had achieved deep remission.

In clinical practice, physicians may encounter questions about the feasibility of therapeutic de-escalation in CD patients who have achieved deep remission, on account of safety, adverse events and cost. There is a paucity of data related to the optimum duration and the appropriate time to cease medication after achieving remission in patients with $\mathrm{CD}$, particularly in pediatric patients.

It is now known that early introduction of biologics has tremendous advantages in terms of maintaining tight control of inflammation and catching the therapeutic window ${ }^{16,17}$. A randomized controlled trial (RCT) revealed that co-treatment with IFX and AZA significantly increases the rate of CR and mucosal healing compared to AZA monotherapy in CD patients ${ }^{4}$. In addition, recent studies have reported that endoscopic and histological mucosal healing should be treat-to-target in CD patients instead of symptomatic control to achieve better outcomes and minimize future complications ${ }^{18}$. With the development of treatment strategies, clinicians are being confronted with a crossroads decision about when to stop or reduce the therapy dose once patients achieve remission ${ }^{19}$.

A systematic review of cessation studies for patients with inflammatory bowel disease concluded that about 50 percent of patients who withdrew anti-TNF-a agents after combination therapy with immunomodulators maintained remission for 24 months ${ }^{20}$. Reenaers et al. reported that among patients with CD who withdrew IFX in stable CR state, twenty-one percent did not restart biologics including IFX, and sustained $\mathrm{CR}$ for seven years after infliximab cessation ${ }^{21}$. Therefore, it seems reasonable to conclude that there may be a subgroup of patients who are good candidates for treatment withdrawal.

Our data that IFX cessation in patients with CD was associated with a high risk of clinical relapse is consistent with the results of other previously published studies $22,23,24,25$. A recent retrospective study conducted in Korea on adults evaluated the long-term outcomes following cessation of anti-TNF-a treatment in inflammatory bowel disease (IBD) patients with $\mathrm{CR}^{24}$. After cessation of anti-TNF-a treatment for CD patients, the cumulative relapse rates at 1, 3, and 5 years were $11.3 \%, 46.7 \%$, and $62.5 \%$. In this cohorts, mucosal healing rate before discontinuation of anti-TNF-a treatment in CD patents was 
22.5\%. Another recent retrospective study performed by Luca and colleagues investigated the clinical course after anti-TNF-a treatment discontinuation in selected pediatric patients with IBD who achieved deep remission similar to our study ${ }^{25}$. Among these patients, relapse-free survival rates at 12,24 , and 36 months for CD were $83.3 \%, 71.1 \%$, and $23.7 \%$, respectively. In contrast, none of the patients with CD who maintained anti-TNF-a treatment after achieving mucosal healing experienced clinical relapse ${ }^{24}$. Compared with previous study performed by Luca in which only $12.5 \%$ of patients were treated with combination therapy, all of our subjects were treated with combination therapy and IFX TLs at the timing of IFX withdrawal or last follow-up were found to be $3 \mu \mathrm{g} / \mathrm{mL}$ or higher, confirming that IFX effect was sufficient. Even with these stringent selection criteria, IFX withdrawal in pediatric CD is still inadvisable.

However, the association between discontinuation of AZA and clinical relapse is controversial. In one reported study, which was focused on CD in CR under AZA-IFX combination therapy, AZA cessation was associated with a high risk of relapse in those patients treated with combination therapy for less than 27 months ${ }^{26}$. In contrast, two other RCTs and one meta-analysis suggested that discontinuing AZA from a combination therapy regimen may not differ in clinical relapse rates compared to continuing with combination therapy $8,20,27$. However, both RCTs included subjects comprised primarily of those who had previously failed immunomodulators monotherapy. It could be argued that in this cohort, the subsequent cessation of this agent would not be expected to have a significant effect compared to a patient cohort in which patients were initially treated with combination therapy ${ }^{9}$. Nevertheless, most studies of patients with $C D$ who discontinued AZA after combination therapy revealed that there were no differences between AZA withdrawal from combination therapy and continuation of combination therapy in terms of clinical relapse. In addition, the European Crohn's and colitis organization guideline provide the opinion that AZA withdrawal in patients treated with combination therapy is inappropriate in patients with high risk/refractory disease or in patients at risk of biologic failure ${ }^{28}$. In other words, it can be said that in patients with sustained deep remission, controlled disease activity and low risk of biologic failure, azathioprine could be withdrawn.

When subjects were treated with combination therapy and maintained CR for at least two years, mucosal healing was observed in $82.7 \%$ and deep remission was achieved in $41.3 \%$ in our study. Based on these findings, we attempted drug cessation assuming that most of the patients who satisfied both conditions had received sufficient treatment and had a low risk of relapse. In our study, AZA cessation was not shown to increase the risk of clinical relapse (HR 1.078,95\% Cl=0.327-3.55, $P=0.9021)$. This result could be partially explained by another study which revealed that withdrawal of AZA after at least six months of combination therapy does not reduce the TL of IFX in patients with $C D{ }^{29}$. The mean durations of AZA therapy were $38 \pm 19.3$ months. We also wanted to know the change in the risk of relapse according to the treatment duration with AZA, but the number of patients who discontinued AZA was small, so further statistical analysis was impossible.

According to our results and those of other reports, IFX TL and 6-TGN level affect clinical relapse ${ }^{30,31}$. High drug concentrations within the therapeutic range could be a factor in lowering the risk of relapse. 
Pursuing a high therapeutic concentration may lead to concerns about adverse drug reactions. However, using therapeutic drug monitoring (TDM) for personalizing therapy for CD patients, drug concentration could be maintained within the therapeutic range. The average IFX TL and 6-TGN level during the followup period were $6.1 \pm 5.4 \mu \mathrm{g} / \mathrm{mL}$ and $208.5 \pm 114.2 \mathrm{pmol} / 8 \times 10^{8} \mathrm{RBC}$ respectively. Since patients who were poor metabolizers of AZA and primary non-responders to IFX were excluded from this study, the relationship between higher drug concentrations above therapeutic range of 6-TGN and occurrence of adverse events was not addressed in this study.

In adults, the development of ATI occurs in up to $65.3 \%$ in patients with IBD ${ }^{32}$, while ATI have been reported in $8-43 \%$ of pediatric patients with IBD ${ }^{33}$. The results of our study are consistent with these data, as the formation of ATI was detected in $12.0 \%$ of patients receiving combination therapy. The development of ATI can neutralize IFX by direct binding of neutralizing antibodies, or accelerating the clearance of the IFX by the binding of non-neutralizing antibodies ${ }^{34,35}$. These mechanisms lower IFX TL and can lead to loss of response during IFX administration ${ }^{35}$. Similarly in our study, patients with ATI formation had a lower relapse free survival rate than those with negative ATI (Fig. 3C).

It is well known that concomitant use of immunomodulators reduces ATI formation, and improves the pharmacokinetics of IFX 8,37,38. However, other factors affecting ATI formation were not clearly identified. We specifically asked whether there is a relationship between the factors affecting clinical relapse and ATI formation. According to our analysis, only 6-TGN level was associated with an increased risk of formation of ATI and this result is consistent with another study ${ }^{39}$.

Although the present study is retrospective and relatively small-sized, it sought a more analytical approach to drug cessation and drug concentration. Drug-related factors were analyzed as time-varying covariates rather than time-independent covariates. Conventional survival analysis is generally applied to the time-independent data, where the exposure variables of interest are often treated as time-fixed ${ }^{40}$. However, values of these exposure variables can vary over time and time-fixed analysis may cause bias over time potentially altering the conclusions of the study. To the best of our knowledge, none of the studies to determine when to withdraw drugs in patients with $C D$ have used time-varying covariates $8,9,21,23,26,28,29$. The factors which are known to affect relapse such as 6-TGN level, IFX TLs, ATI formation, and timing of drug cessation are all variables that change with time after patient observation starts, therefore, the time-varying covariate approach is preferable for survival analysis in our study. This method increased the reliability of the study because it avoids biases associated with different timing of drug cessation in different patients.

The current study has a few limitations. First, this was a single-center, retrospective study and, consequently, had relatively unstructured follow-up of patients with certain limitations compared to studies using prospective design. However, all subjects received regular examinations such as endoscopy and biopsy on the same principles and IFX TLs or 6-TGN were examined at regular intervals. Therefore, the extraction of clinical disease activity using PCDAl, laboratory results, endoscopic and histologic 
results from medical records was possible at all outpatient visits. Although the decision to withdraw either IFX or AZA was not randomly assigned, however there was no difference in disease activity and baseline. Moreover, our findings are meaningful because these are real-world data from a single center cohort. Second, selection bias might have been introduced because the number of participating patients was relatively small and the observation period was not as long as might be desired. Also, because of adverse events such as lymphoma that may occur in male patients with long-term use of AZA, the group who withdrew AZA had a statistically larger number of male patients than the group who discontinued IFX, resulting in a selection bias of gender. Third, since multiple time-varying covariates made multivariate analysis too complicated to perform, only univariate results were presented.

Despite these limitations, our study reports the outcome of drug cessation in strictly selected cohort who sustained sufficient CR and achieved deep remission in real clinical settings. Maintaining the 6-TGN level and IFX TL high within the therapeutic range lowers the risk of clinical relapse and IFX cessation and ATI formation increase the risk of clinical relapse. In conclusion, even when applied in pediatric patients who meet strict criteria after a sufficient CR period and deep remission, IFX cessation in pediatric CD should be considered more carefully. However, withdrawal of AZA could be contemplated in selected pediatric patients with CD sustaining CR for at least two years and achieved deep remission.

\section{Declarations}

\section{Acknowledgments None}

\section{Funding}

This work was supported by the National Research Foundation of Korea (NRF) grant funded by the Korea government (MSIT) (No. 2020R1A2C2007192).

\section{Conflict of Interest}

The authors declare no competing interests.

\section{Author Contributions}

\section{Guarantor of article: Eun Sil Kim}

TJJ and ESK contributed to the conception and design of the study, acquisition, analysis, and interpretation of data, drafting of the initial manuscript, and critical revision of the manuscript for important intellectual contribution. Y-YK contributed to the analysis and interpretation of data. S-WK contributed to the study design, statistical analyses and interpretation of data, and critical revision of the manuscript for important intellectual contribution. SWS contributed to design of the study and interpretation of data. YHC and MJK contributed to the conception and design of the study, analysis and interpretation of data, and critical revision of the manuscript for important intellectual contribution. All 
authors approved the final version of the manuscript, had full access to all the data in the study, and had final responsibility for the decision to submit for publication.

\section{Ethics declarations}

This study was approved by the Institutional Review Board of the Samsung Medical Center (IRB file No. 2020-06-128-001), and was conducted in accordance with the Declaration of Helsinki. All patients and parents and/or legal guardian of subjects who are under 18 provided written informed consent. We confirmed that all methods were performed in accordance with the approved guidelines and regulations. We reported and presented data according to the STROBE statement.

\section{References}

1. Cosnes J, Cattan S, Blain A, et al. Long-term evolution of disease behavior of Crohn's disease. Inflamm Bowel Dis. 2002;8:244-250.

2. Walters TD, Kim MO, Denson LA, et al. Increased effectiveness of early therapy with anti-tumor necrosis factor-alpha vs an immunomodulator in children with Crohn's disease. Gastroenterology. 2014;146:383-391.

3. Bouguen G, Huguet A, Amiot A, et al. Efficacy and Safety of Tumor Necrosis Factor Antagonists in Treatment of Internal Fistulizing Crohn's Disease. Clin Gastroenterol Hepatol. 2020;18:628-636.

4. Colombel JF, Sandborn WJ, Reinisch W, et al. Infliximab, azathioprine, or combination therapy for Crohn's disease. N Engl J Med. 2010;362:1383-1395.

5. Khanna R, Bressler B, Levesque BG, et al. Early combined immunosuppression for the management of Crohn's disease (REACT): a cluster randomised controlled trial. Lancet. 2015;386:1825-1834.

6. Ashworth LA, Billett A, Mitchell P, Nuti F, Siegel C, Bousvaros A. Lymphoma risk in children and young adults with inflammatory bowel disease: analysis of a large single-center cohort. Inflamm Bowel Dis. 2012;18:838-843.

7. Smith MA, Irving PM, Marinaki AM, Sanderson JD. Review article: malignancy on thiopurine treatment with special reference to inflammatory bowel disease. Aliment Pharmacol Ther. 2010;32:119-130.

8. Van Assche G, Magdelaine-Beuzelin C, D'Haens G, et al. Withdrawal of immunosuppression in Crohn's disease treated with scheduled infliximab maintenance: a randomized trial. Gastroenterology. 2008;134:1861-1868.

9. Boyapati RK, Torres J, Palmela C, et al. Withdrawal of immunosuppressant or biologic therapy for patients with quiescent Crohn's disease. Cochrane Database Syst Rev. 2018;5:CD012540.

10. Vermeire S, Noman M, Van Assche G, Baert F, D'Haens G, Rutgeerts P. Effectiveness of concomitant immunosuppressive therapy in suppressing the formation of antibodies to infliximab in Crohn's disease. Gut. 2007;56:1226-1231. 
11. Levine A, Koletzko S, Turner D, et al. ESPGHAN revised porto criteria for the diagnosis of inflammatory bowel disease in children and adolescents. J Pediatr Gastroenterol Nutr. 2014;58:795806.

12. Levine A, Griffiths A, Markowitz J, et al. Pediatric modification of the Montreal classification for inflammatory bowel disease: the Paris classification. Inflamm Bowel Dis. 2011;17:1314-1321.

13. Black AJ, McLeod HL, Capell HA, et al. Thiopurine methyltransferase genotype predicts therapylimiting severe toxicity from azathioprine. Ann Intern Med. 1998;129:716-718.

14. Dervieux T, Meyer G, Barham R, et al. Liquid chromatography-tandem mass spectrometry analysis of erythrocyte thiopurine nucleotides and effect of thiopurine methyltransferase gene variants on these metabolites in patients receiving azathioprine/6-mercaptopurine therapy. Clin Chem. 2005;51:20742084.

15. Snapinn SM, Jiang Q, Iglewicz B. Illustrating the Impact of a Time-Varying Covariate With an Extended Kaplan-Meier Estimator. Am Stat. 2005;59:301-307.

16. Levesque BG, Sandborn WJ, Ruel J, Feagan BG, Sands BE, Colombel JF. Converging goals of treatment of inflammatory bowel disease from clinical trials and practice. Gastroenterology. 2015;148:37-51 e31.

17. Kang B, Choi SY, Kim HS, Kim K, Lee YM, Choe YH. Mucosal Healing in Paediatric Patients with Moderate-to-Severe Luminal Crohn's Disease Under Combined Immunosuppression: Escalation versus Early Treatment. J Crohns Colitis. 2016;10:1279-1286.

18. Gupta A, Yu A, Peyrin-Biroulet L, Ananthakrishnan AN. Treat to Target: The Role of Histologic Healing in Inflammatory Bowel Diseases, A Systematic Review and Meta-Analysis. Clin Gastroenterol Hepatol. 2020.

19. Peyrin-Biroulet L, Sandborn W, Sands BE, et al. Selecting Therapeutic Targets in Inflammatory Bowel Disease (STRIDE): Determining Therapeutic Goals for Treat-to-Target. Am J Gastroenterol. 2015;110:1324-1338.

20. Choe YH. Precision medicine for pediatric inflammatory bowel disease: a perspective. Precision Future Med. 2020;4:43-52.

21. Torres J, Boyapati RK, Kennedy NA, Louis E, Colombel JF, Satsangi J. Systematic Review of Effects of Withdrawal of Immunomodulators or Biologic Agents From Patients With Inflammatory Bowel Disease. Gastroenterology. 2015;149:1716-1730.

22. Reenaers C, Mary JY, Nachury M, et al. Outcomes 7 Years After Infliximab Withdrawal for Patients With Crohn's Disease in Sustained Remission. Clin Gastroenterol Hepatol. 2018;16:234-243.e232.

23. Brooks AJ, Sebastian S, Cross SS, et al. Outcome of elective withdrawal of anti-tumour necrosis factor-alpha therapy in patients with Crohn's disease in established remission. $J$ Crohns Colitis. 2017; 11:1456-1462.

24. Song JH, Kang EA, Park SK, et al. Long-term Outcomes after the Discontinuation of Anti-Tumor Necrosis Factor-a Therapy in Patients with Inflammatory Bowel Disease under Clinical Remission: A Korean Association for the Study of Intestinal Disease Multicenter Study. Gut Liver 2021. 
25. Scarallo L, Bolasco G, Barp J, et al. Anti-Tumor Necrosis Factor-Alpha Withdrawal in Children With Inflammatory Bowel Disease in Endoscopic and Histologic Remission. Inflamm Bowel Dis 2021.

26. Oussalah A, Chevaux JB, Fay R, Sandborn WJ, Bigard MA, Peyrin-Biroulet L. Predictors of infliximab failure after azathioprine withdrawal in Crohn's disease treated with combination therapy. Am J Gastroenterol. 2010;105:1142-1149.

27. Roblin X, Boschetti G, Williet N, et al. Azathioprine dose reduction in inflammatory bowel disease patients on combination therapy: an open-label, prospective and randomised clinical trial. Aliment Pharmacol Ther. 2017;46:142-149.

28. Doherty G, Katsanos KH, Burisch J, et al. European Crohn's and Colitis Organisation Topical Review on Treatment Withdrawal ['Exit Strategies'] in Inflammatory Bowel Disease. J Crohns Colitis. 2018;12:17-31.

29. Drobne D, Bossuyt P, Breynaert C, et al. Withdrawal of immunomodulators after co-treatment does not reduce trough level of infliximab in patients with Crohn's disease. Clin Gastroenterol Hepatol. 2015;13:514-521.e514.

30. Maser EA, Villela R, Silverberg MS, Greenberg GR. Association of trough serum infliximab to clinical outcome after scheduled maintenance treatment for Crohn's disease. Clin Gastroenterol Hepatol. 2006;4:1248-1254.

31. Baert $F$, Noman $M$, Vermeire $S$, et al. Influence of immunogenicity on the long-term efficacy of infliximab in Crohn's disease. N Engl J Med. 2003;348:601-608.

32. Vermeire S, Gils A, Accossato P, Lula S, Marren A. Immunogenicity of biologics in inflammatory bowel disease. Therap Adv Gastroenterol. 2018;11:1756283X17750355.

33. Carman N, Mack DR, Benchimol El. Therapeutic Drug Monitoring in Pediatric Inflammatory Bowel Disease. Curr Gastroenterol Rep. 2018;20:18.

34. Ordas I, Mould DR, Feagan BG, Sandborn WJ. Anti-TNF monoclonal antibodies in inflammatory bowel disease: pharmacokinetics-based dosing paradigms. Clin Pharmacol Ther. 2012;91:635-646.

35. Rosen MJ, Minar P, Vinks AA. Review article: applying pharmacokinetics to optimise dosing of antiTNF biologics in acute severe ulcerative colitis. Aliment Pharmacol Ther. 2015;41:1094-1103.

36. Ben-Horin S, Chowers Y. Review article: loss of response to anti-TNF treatments in Crohn's disease. Aliment Pharmacol Ther. 2011;33:987-995.

37. Kansen HM, van Rheenen PF, Houwen RHJ, et al. Less Anti-infliximab Antibody Formation in Paediatric Crohn Patients on Concomitant Immunomodulators. J Pediatr Gastroenterol Nutr. 2017;65:425-429.

38. Colombel JF, Adedokun OJ, Gasink C, et al. Combination Therapy With Infliximab and Azathioprine Improves Infliximab Pharmacokinetic Features and Efficacy: A Post Hoc Analysis. Clin Gastroenterol Hepatol. 2019;17:1525-1532 e1521.

39. Mogensen DV, Brynskov J, Ainsworth MA, Nersting J, Schmiegelow K, Steenholdt C. A Role for Thiopurine Metabolites in the Synergism Between Thiopurines and Infliximab in Inflammatory Bowel Disease. J Crohns Colitis. 2018;12:298-305. 
40. van Walraven C, Davis D, Forster AJ, Wells GA. Time-dependent bias was common in survival analyses published in leading clinical journals. J Clin Epidemiol. 2004;57:672-682.

\section{Tables}

Table 1 Baseline clinical characteristics of study patients 


\begin{tabular}{|c|c|}
\hline & Total $(n=75)$ \\
\hline \multicolumn{2}{|l|}{ Gender, $n(\%)$} \\
\hline Male & $48(64.0)$ \\
\hline Female & $27(36.0)$ \\
\hline Observational period, months & $41.5(23.0,58.7)$ \\
\hline Age at diagnosis, years & $14.2(12.0,17.0)$ \\
\hline \multicolumn{2}{|l|}{ Age group, $\mathrm{n}(\%)$} \\
\hline $5-9$ years & $5(6.6)$ \\
\hline $10-14$ years & $35(46.7)$ \\
\hline $15-19$ years & $35(46.7)$ \\
\hline Initial BMI at diagnosis, $\mathrm{kg} / \mathrm{m}^{2}$ & $19.0(16.8,20.7)$ \\
\hline Initial PCDAl at diagnosis & $39.7(37.5,45.0)$ \\
\hline \multicolumn{2}{|l|}{ Disease location, $\mathrm{n}(\%)$} \\
\hline Ileal (L1) & $9(12.0)$ \\
\hline Colonic (L2) & $3(4.0)$ \\
\hline Ileocoloninc (L3) & $61(81.3)$ \\
\hline \multicolumn{2}{|l|}{ Upper gastrointestinal involvement, n (\%) } \\
\hline None & $1(1.3)$ \\
\hline Proximal to the ligament of Treitz $(\mathrm{L} 4 \mathrm{a})$ & $9(12.0)$ \\
\hline Distal to the ligament of Treitz and proximal to the distal $1 / 3$ ileum ( $L 4 b)$ & $9(12.0)$ \\
\hline Both (L4ab) & $56(74.7)$ \\
\hline \multicolumn{2}{|l|}{ Behavior of disease, $n(\%)$} \\
\hline Inflammatory (B1) & $52(69.3)$ \\
\hline Stricturing (B2) & $20(26.7)$ \\
\hline Penetrating (B2/B3) & $3(4.0)$ \\
\hline \multicolumn{2}{|l|}{ Growth } \\
\hline No evidence of growth delay(G0) & $51(68.0)$ \\
\hline Growth delay(G1) & $24(32.0)$ \\
\hline Active perianal lesion, $\mathrm{n}(\%)$ & $43(57.3)$ \\
\hline
\end{tabular}




\begin{tabular}{ll|} 
Initial Laboratory findings & \\
White blood cell count, $\times 10^{3} / \mu \mathrm{L}$ & $8.8(6.7,11.1)$ \\
Hematocrit, $\%$ & $36.8(33.4,39.8)$ \\
Platelet count, $\times 10^{3} / \mu \mathrm{L}$ & $382(309,491)$ \\
Erythrocyte sedimentation rate, $\mathrm{mm} / \mathrm{hr}$ & $55.0(29.5,77.5)$ \\
C-reactive protein, $\mathrm{mg} / \mathrm{dL}$ & $3.1(0.8,4.3)$ \\
Albumin, $\mathrm{g} / \mathrm{dL}$ & $3.8(3.4,4.3)$ \\
Initial SES-CD at diagnosis & $16.9(11.0,24.0)$ \\
Concomitant medication , $\mathbf{n}(\%)$ &
\end{tabular}

Baseline characteristics of subjects were explored with descriptive statistics through frequencies (proportion) for categorical variables or medians (interquartile range[IQR]) for continuous variables.

Abbreviations: BMI, body mass index; PCDAl, pediatric Crohn's disease activity index; SES-CD, simple endoscopic score for Crohn's disease; 6-TGN, 6-thioguanine nucleotide.

Table 2. Comparison of patients between infliximab or azathioprine withdrawal groups 


\begin{tabular}{|c|c|c|c|c|}
\hline & $\begin{array}{l}\text { IFX } \\
\text { withdrawal } \\
\text { group }\end{array}$ & $\begin{array}{l}\text { AZA withdrawal } \\
\text { group }\end{array}$ & $\begin{array}{l}\text { IFX and AZA } \\
\text { withdrawal group }\end{array}$ & $\begin{array}{l}\mathrm{p}- \\
\text { value }\end{array}$ \\
\hline Number of patients (\%) & $15(48.4)$ & $10(32.2)$ & $6(19.4)$ & \\
\hline Sex, male (\%) & $7(31.8)$ & $9(40.9)$ & $6(27.3)$ & 0.018 \\
\hline \multicolumn{5}{|l|}{ Initial laboratory findings } \\
\hline $\begin{array}{l}\text { White blood cell count, } \times 10^{3} / \\
\mu \mathrm{L}\end{array}$ & $\begin{array}{l}7.80(7.43 \\
9.71)\end{array}$ & $\begin{array}{l}9.29(8.23 \\
10.72)\end{array}$ & $8.61(7.80,9.19)$ & 0.673 \\
\hline Hematocrit, \% & $\begin{array}{l}35.6(33.1 \\
39.1)\end{array}$ & $35.2(32.3,39.1)$ & $40.0(37.9,41.7)$ & 0.069 \\
\hline $\begin{array}{l}\text { Erythrocyte sedimentation } \\
\text { rate, } \mathrm{mm} / \mathrm{hr}\end{array}$ & $\begin{array}{l}53.0(41.5 \\
78.0)\end{array}$ & $63.0(39.3,83.5)$ & $25.0(23.0,29.3)$ & 0.071 \\
\hline C-reactive protein, $\mathrm{mg} / \mathrm{dL}$ & $\begin{array}{l}1.21(0.64 \\
7.60)\end{array}$ & $2.37(1.84,3.52)$ & $2.33(1.10,3.46)$ & 0.712 \\
\hline Albumin, g/dL & $3.8(3.6,4.3)$ & $3.8(3.5,4.3)$ & $4.2(4.0,4.4)$ & 0.479 \\
\hline Initial PCDAI & $\begin{array}{l}40.0(33.3 \\
46.3)\end{array}$ & $35(30.6,41.9)$ & $35.0(30.0,41.0)$ & 0.515 \\
\hline Initial SES-CD & $\begin{array}{l}16.0(11.5 \\
19.5)\end{array}$ & $18.0(14.3,24.0)$ & $13.5(7.0,17.8)$ & 0.298 \\
\hline \multicolumn{5}{|l|}{$\begin{array}{l}\text { Laboratory findings } \\
\text { at IFX or AZA withdrawal }\end{array}$} \\
\hline $\begin{array}{l}\text { White blood cell count, } \times 10^{3} / \\
\mu \mathrm{L}\end{array}$ & $\begin{array}{l}5.52(4.80 \\
7.07)\end{array}$ & $6.11(5.45,6.88)$ & $5.67(5.11,5.82)$ & 0.830 \\
\hline Hematocrit, \% & $\begin{array}{l}39.4(37.1 \\
43.8)\end{array}$ & $45.4(44.5,46.6)$ & $43.2(42.5,45.5)$ & 0.174 \\
\hline $\begin{array}{l}\text { Erythrocyte sedimentation } \\
\text { rate, } \mathrm{mm} / \mathrm{hr}\end{array}$ & $\begin{array}{l}12.0(4.5 \\
20.5)\end{array}$ & $4.5(2.3,9.0)$ & $5.0(2.8,11.8)$ & 0.243 \\
\hline C-reactive protein, $\mathrm{mg} / \mathrm{dL}$ & $\begin{array}{l}0.03(0.03 \\
0.08)\end{array}$ & $0.04(0.03,0.04)$ & $0.13(0.03,0.36)$ & 0.437 \\
\hline Albumin, g/dL & $4.5(4.4,4.7)$ & $4.7(4.6,4.9)$ & $4.5(4.5,4.6)$ & 0.196 \\
\hline $\begin{array}{l}\text { PCDAl at IFX or AZA } \\
\text { withdrawal }\end{array}$ & $0(0,0)$ & $0(0,0)$ & $0(0,0)$ & 0.669 \\
\hline $\begin{array}{l}\text { SES-CD at IFX or AZA } \\
\text { withdrawal }\end{array}$ & $0(0,0.45)$ & $0(0,0)$ & $0(0,0.25)$ & 0.496 \\
\hline
\end{tabular}

Baseline characteristics of subjects who withdrew infliximab or azathioprine were explored with descriptive statistics through frequencies (proportion) for categorical variables or medians (interquartile 
range[IQR]) for continuous variables.

Abbreviations: PCDAl, Pediatric Crohn's disease activity index; SES-CD, Simple endoscopic score for Crohn's disease; AZA, azathioprine; IFX, infliximab;

Table 3 Factors affecting clinical relapse in pediatric patients with Crohn's disease

\begin{tabular}{|c|c|c|c|}
\hline Variables & Hazard ratio & 95\% Cl for hazard ratio & $p$-value \\
\hline Age & 0.965 & $0.854-1.091$ & 0.5666 \\
\hline \multirow[b]{2}{*}{ Female } & \multicolumn{3}{|l|}{ Reference } \\
\hline & 1.203 & $0.579-2.500$ & 0.6204 \\
\hline \multicolumn{4}{|l|}{ Initial laboratory findings } \\
\hline White blood cell counts & 1.000 & $0.997-1.000$ & 0.070 \\
\hline Hematocrit & 0.960 & $0.891-1.035$ & 0.287 \\
\hline Albumin & 0.751 & $0.409-1.381$ & 0.357 \\
\hline Erythrocyte sedimentation rate & 1.021 & $1.005-1.036$ & 0.084 \\
\hline C-reactive protein & 0.916 & $0.809-1.037$ & 0.167 \\
\hline Initial PCDAI & 1.002 & $0.957-1.049$ & 0.941 \\
\hline Initial SES-CD & 0.984 & $0.926-1.045$ & 0.594 \\
\hline Initial disease phenotype & \multicolumn{3}{|l|}{ Reference } \\
\hline L2 (Colonic) & 4.934 & $0.515-46.234$ & 0.166 \\
\hline Initial disease behavior & \multicolumn{3}{|l|}{ Reference } \\
\hline B2 (Inflammatory) & 0.920 & $0.400-2.112$ & 0.843 \\
\hline Initial growth impairment & 0.602 & $0.251-1.442$ & 0.255 \\
\hline *AZA cessation & 1.078 & $0.327-3.550$ & 0.9021 \\
\hline *IFX cessation & 2.928 & $1.322-6.485$ & 0.0081 \\
\hline *Mesalazine cessation & 1.165 & $0.517-2.627$ & 0.7129 \\
\hline *antibody-to-IFX formation & 3.120 & $1.069-9.103$ & 0.0373 \\
\hline *6-TGN level & 0.978 & $0.968-0.987$ & $<0.0001$ \\
\hline *IFX Trough level & 0.581 & $0.432-0.781$ & 0.0003 \\
\hline
\end{tabular}

The risk factors associated with clinical relapse were identified by Cox proportional-hazards regression models. In this model, cessation and duration of medication, 6-TGN, and IFX TL were analyzed as time- 
varying covariates. Hazard ratio (HR) for each variable was derived within the $95 \%$ confidence intervals (Cls).

* Variables were analyzed as time varying covariates

Abbreviations: PCDAl, pediatric Crohn's disease activity index; SES-CD, simple endoscopic score for Crohn's disease; AZA, azathioprine; IFX, infliximab; 6-TGN, 6-thioguanine nucleotide

\section{Table 4 Factors affecting development of antibody-to-infliximab}

\begin{tabular}{|c|c|c|c|}
\hline Variables & Hazard ratio & $95 \% \mathrm{Cl}$ for hazard ratio & $p$-value \\
\hline Age & 1.132 & $0.872-1.468$ & 0.3511 \\
\hline \multirow[b]{2}{*}{ Female } & \multicolumn{3}{|l|}{ Reference } \\
\hline & 1.528 & $0.410-5.670$ & 0.528 \\
\hline \multicolumn{4}{|l|}{ Initial laboratory findings } \\
\hline White blood cell counts & 1.000 & $0.999-1.000$ & 0.530 \\
\hline Hematocrit & 1.033 & $0.899-1.188$ & 0.647 \\
\hline Albumin & 0.860 & $0.303-2.444$ & 0.778 \\
\hline Erythrocyte sedimentation rate & 1.004 & $0.983-1.025$ & 0.723 \\
\hline C-reactive protein & 0.994 & $0.814-1.214$ & 0.950 \\
\hline Initial PCDAI & 1.001 & $0.942-1.063$ & 0.982 \\
\hline Initial SES-CD & 0.948 & $0.873-1.030$ & 0.204 \\
\hline Initial disease phenotype & \multicolumn{3}{|l|}{ Reference } \\
\hline L2 (Colonic) & 1.664 & $0.150-18.410$ & 0.678 \\
\hline Initial disease behavior & \multicolumn{3}{|l|}{ Reference } \\
\hline B2 (Inflammatory) & 0.643 & $0.134-3.094$ & 0.582 \\
\hline Initial growth impairment & 1.086 & $0.274-4.345$ & 0.907 \\
\hline *AZA cessation & 17.990 & $0.190-1663.7$ & 0.2109 \\
\hline *6-TGN level & 0.988 & $0.980-0.996$ & 0.0048 \\
\hline
\end{tabular}

The risk factors associated with formation of ATI were identified by Cox proportional-hazards regression models. In this model, cessation of medication and 6-TGN were analyzed as time-varying covariates. Hazard ratio (HR) for each variable was derived within the $95 \%$ confidence intervals (Cls).

* Variables were analyzed as time varying covariates 


\section{Figures}

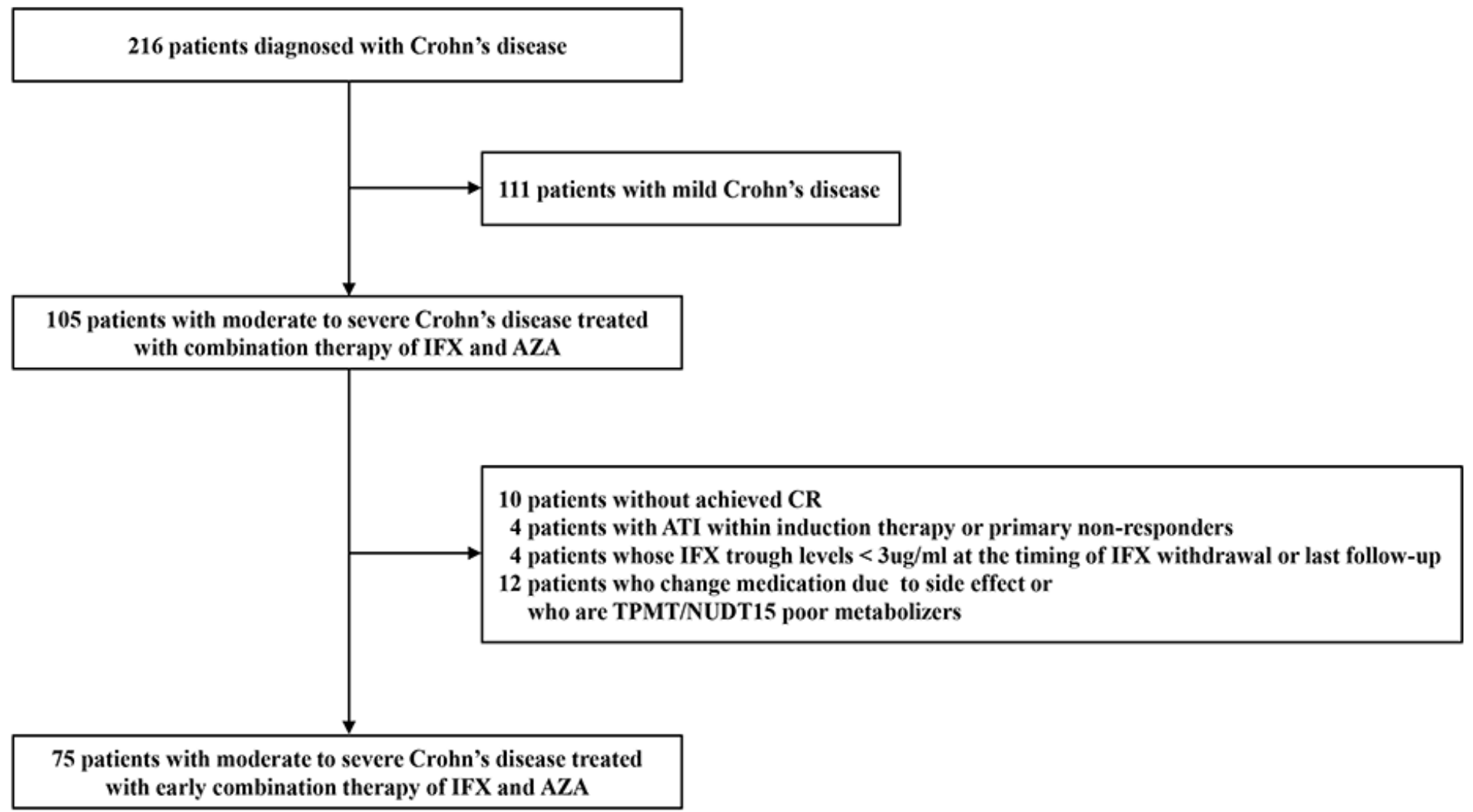

Abbreviations: infliximab; IFX, azathioprine; AZA, clinical remission; CR, antibody-to-infliximab; ATI, thiopurine methyltransferase; TPMT, nucleotide triphosphate diphosphatase 15; NUDT15

\section{Figure 1}

Flow diagram showing patient selection process Abbreviations: AZA, azathioprine; IFX, infliximab; ATI, antibody-to-infliximab 


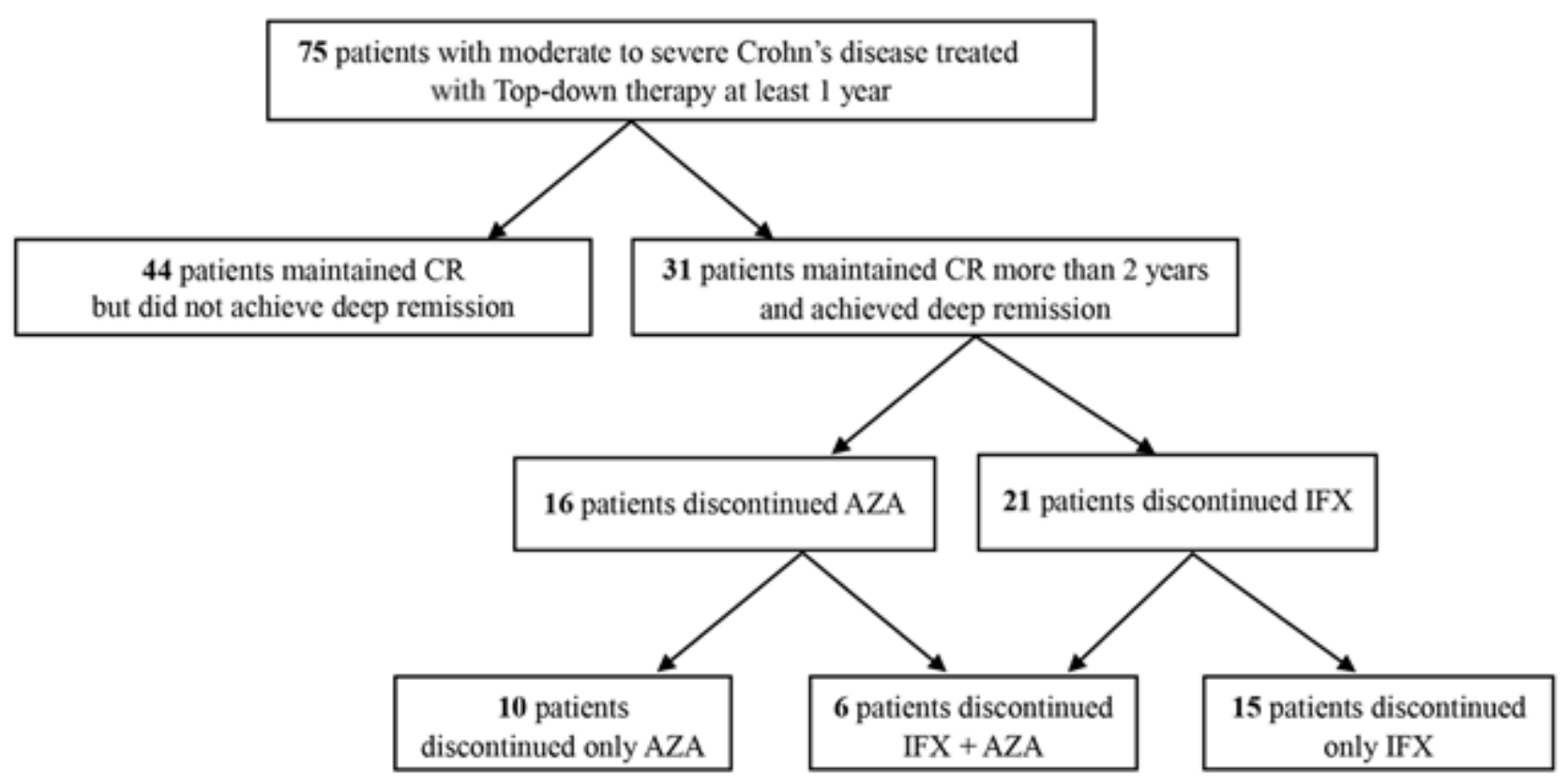

\section{Figure 2}

Study flow diagram Abbreviations: CR, clinical remission; AZA, azathioprine; IFX, infliximab

(A)

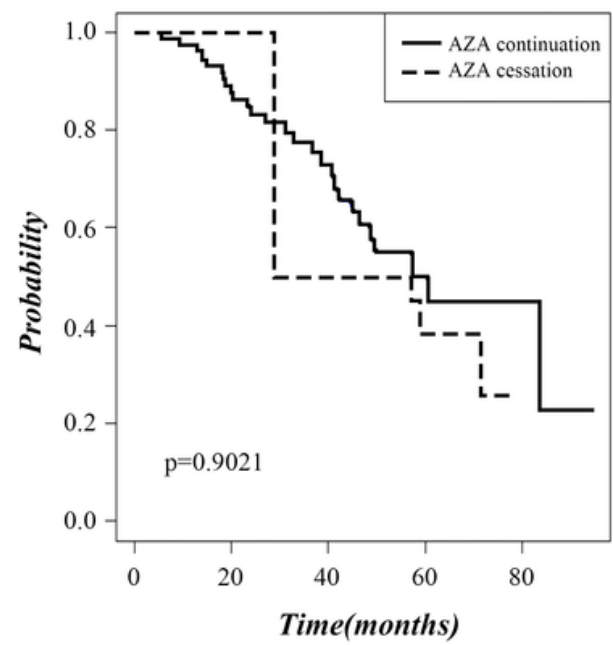

(B)

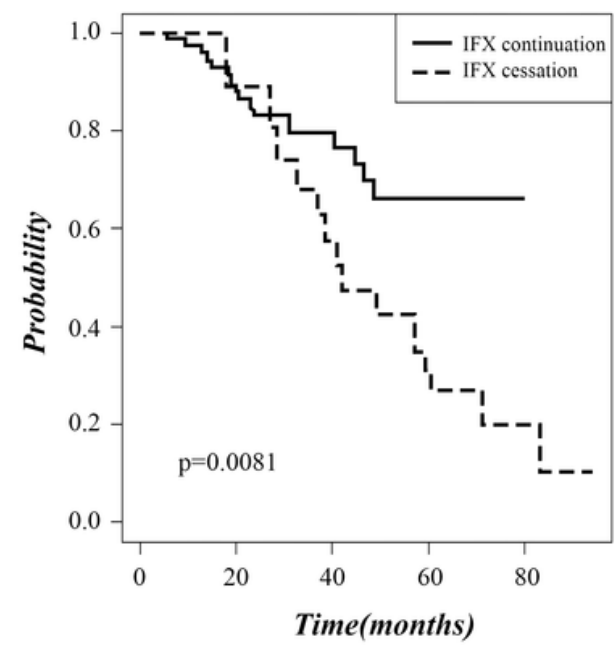

(C)

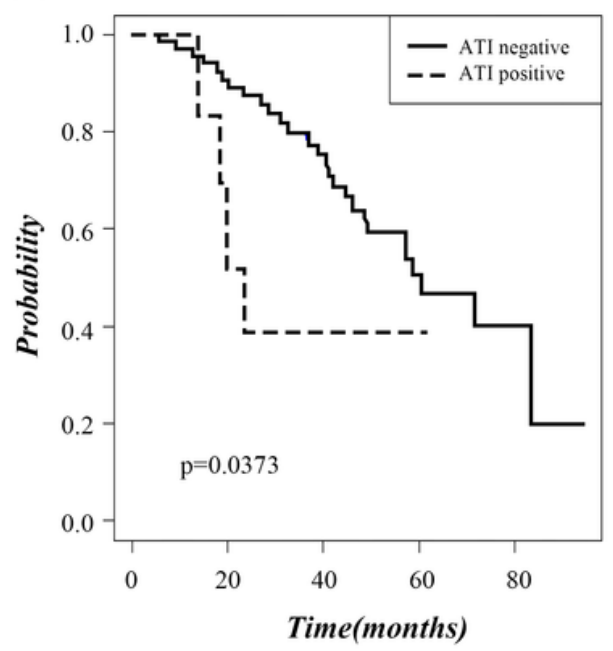

\section{Figure 3}

Relapse-free curve according to drug cessation and development of antibody-to-infliximab Abbreviations: AZA, azathioprine; IFX, infliximab; ATI, antibody-to-infliximab 